\title{
Availability and cost of major and first-line antiepileptic drugs: a comprehensive evaluation in the capital of Madagascar
}

Jeremy Jost ${ }^{*}$, Adeline Raharivelo ${ }^{1,2}$, Voa Ratsimbazafy ${ }^{1}$, Mandy Nizard ${ }^{1}$, Emilie Auditeau' ${ }^{1}$, Charles R. Newton ${ }^{3,4}$ and Pierre-Marie Preux ${ }^{1}$

\begin{abstract}
Background: The prevalence of epilepsy is high in Madagascar (23.5/1000), as is the treatment gap (estimated at $92 \%)$. The health system of the country is underfunded; some AEDs are used, and the national drug policy does not encourage price regulation or the administration of generic agents. We conducted a cross-sectional study to assess the availability and cost of solid oral AED formulations in Antananarivo, capital of Madagascar. Data were gathered from all officially registered pharmacies (according to the drug agency list, updated in 2015) by means of telephone interviews lasting no more than 10 min and conducted by a native Malagasy speaker. With regard to other sources (hospitals, illicit sales) data were obtained at specific visits. The study received ethical approval from the Madagascar Ministry of Health.
\end{abstract}

Findings: A total of 91 of 100 pharmacies (the nine not included were because of an inoperative phone number), two of three public hospitals, and two illegal outlets were investigated. Sodium valproate was available in $84.6 \%$ of the pharmacies, while carbamazepine and phenobarbital were available in $68.1 \%$ and $36.3 \%$ of the pharmacies, respectively, but phenytoin was not available in any supply chain. There were more originator brands than generic formulations, with a higher cost (range 20.3-81.1\%, median 40.7\%) compared to the equivalent generic. The public system had only a very limited choice of AED, but offered the lowest costs. Illicit sources were more expensive by $54.3 \%$ for carbamazepine and $62.5 \%$ for phenobarbital. Concerning the annual cost of treatment, the average percentage of the gross national income per capita based on the purchasing power parity was 29.8\%/19.0 \% (brand/generic) for sodium valproate, $16.4 \% / 7.3 \%$ (brand/generic) for carbamazepine, $8.9 \% / 5.1 \%$ (brand/generic) for phenobarbital.

Conclusions: The main sources of AEDs were private pharmacies, but the stocks held were low. The financial burden was still important in the capital of Madagascar, mainly the consequence of a highly developed private sector at the expense of the public sector. Although sodium valproate remains the most expensive solution, it still remains the most available instead of phenobarbital. The most striking feature of this study concerns the cost of AEDs in the informal sector, mostly used because they are deemed to provide less costly drugs, the opposite was observed there. The assessment of the cost and availability of medicines was easily and quickly implemented. It provided a relevant focus of the situation in areas difficult to investigate, in terms of road network and geographical situation.

\footnotetext{
*Correspondence: jostjeremy@gmail.com

1 INSERM, Univ. Limoges, CHU Limoges, Department of Pharmacy, UMR_S

1094, Tropical Neuroepidemiology, Institute of Neuroepidemiology

and Tropical Neurology, CNRS FR 3503 GEIST, 2 rue du Docteur Marcland,

87025 Limoges Cedex, France

Full list of author information is available at the end of the article
} 


\section{Background}

Epilepsy is a chronic neurological disease affecting more than 70 million people worldwide (Ngugi et al. 2010). Among them, nearly $90 \%$ live in resource-limited settings where problems of accessibility, affordability and availability of antiepileptic drugs are dramatic. In those areas, the treatment gap (proportion of people with epilepsy who require treatment but do not receive it) has been established to be over $75 \%$ (Meyer et al. 2010). Primary healthcare is extremely limited in developing countries, where only a small proportion of major and first-line antiepileptic drugs (AEDs) are commonly used: phenobarbital, carbamazepine, sodium valproate, phenytoin. The burden is even more dramatic in rural areas where in addition to a low availability the sustainability of drugs supply is often not guaranteed (Perucca 2007). This situation could also be seen in developed European countries where the median availability of all type of AEDs (older and newer) is $82 \%$ ranging from 48 to $100 \%$ (Baftiu and Johannessen 2015). Madagascar is not spared, with a high prevalence of epilepsy (23.5/1000) (Ba-Diop et al. 2014). The treatment gap has been estimated to $92 \%$ by an indirect method (based on the drug consumption over the year) and at $32 \%$ by a direct method (based on how many of the detected cases are not receiving treatment in a prevalence study) (Meyer et al. 2010; Ratsimbazafy et al. 2011; Kale 2002). The health system of the country is underfunded; some antiepileptic drugs (AEDs) are used, but the national drug policy does not encourage price regulation or the administration of generic agents. The total health expenditure in Madagascar was $3.04 \%$ of the Grow Domestic Product which was in 2015 and per capita around 1439 current international \$, adjusted on the purchasing power parity (World Bank data, 2014). Against this background, we conducted a cross-sectional study to assess the availability and cost of solid oral AED formulations in Antananarivo, capital of Madagascar, which had a population of 2.2 million in 2014.

\section{Methods}

This study was performed as an ancillary study of a project aiming at assessing the quality of solid oral AEDs formulations in sub-Saharan Africa, in twelve countries and in all kind of supply chain (official and illegal one). Information on availability and cost was gathered from all officially registered pharmacies (according to the drug agency list, updated in July 2015) by means of telephone interviews lasting no more than $10 \mathrm{~min}$ and conducted by a native Malagasy speaker. With regard to other type of supply chain (hospitals, illicit sales) data were obtained at specific visits. The study received ethical approval from the Madagascar Ministry of Health.

\section{Results}

A total of 91 of 100 pharmacies (the nine not included were because of a wrong/inoperative phone number), two of three public university hospitals, and two illegal outlets were investigated. Sodium valproate was available in $84.6 \%$ of the pharmacies, while carbamazepine and phenobarbital were available in 68.1 and $36.3 \%$ of the pharmacies, respectively, but phenytoin was not available in any supply chain. Availability and costs by AED and dosage are detailed in Table 1. There were more originator brands than generic formulations (e.g. sodium valproate $200 \mathrm{mg}, 84.2 \%$ for originator brand compare to $4.4 \%$ of generic), with a higher cost (range 20.3-81.1\%; median $40.7 \%$ ) compared to the equivalent generic. The public system had only a very limited choice of AED, but offered the lowest costs in the official system $(10.0 \%$ lower for sodium valproate, $36.4 \%$ for carbamazepine and $43.7 \%$ for phenobarbital). Illicit sources were more expensive by $54.3 \%$ for carbamazepine and $62.5 \%$ for phenobarbital; this trend was less marked for sodium valproate. All sources had only one or two boxes of each molecule available. Concerning the annual cost of treatment, the average percentage of the gross national income per capita based on the purchasing power parity (current international \$) was 29.8/19 \% (brand/generic) for sodium valproate, $16.4 / 7.3 \%$ (brand/generic) for carbamazepine, 8.9/5.1 \% (brand/generic) for phenobarbital.

\section{Discussion}

The main sources of AEDs were private pharmacies. Three of the four major AEDs were available, but the stocks held were low. The financial burden for people with epilepsy was still important in the capital of Madagascar. This was mainly the consequence of a very developed private sector at the expense of the public sector, without any price regulation. Originator brand remained more expensive than generic, ranging from 1.3 to 5.3 higher. This result was less dramatic than data observed in a large survey conducted in 46 countries, where originator brand prices were about 30 times higher (Cameron et al. 2012). Furthermore, although sodium valproate remains the most expensive solution, it still remains the most available instead of phenobarbital. However, the most striking feature of this study concerns the cost of AEDs in the informal sector: patients use these outlets mostly because they are deemed to provide less costly drugs, but the opposite was observed in Madagascar. This results must be confirmed by further investigations in other sites but the illicit supply chain is difficult to assess. Selling points are often not officially known, and these information are often obtained by word of mouth. The methodology to measure the cost and availability of 


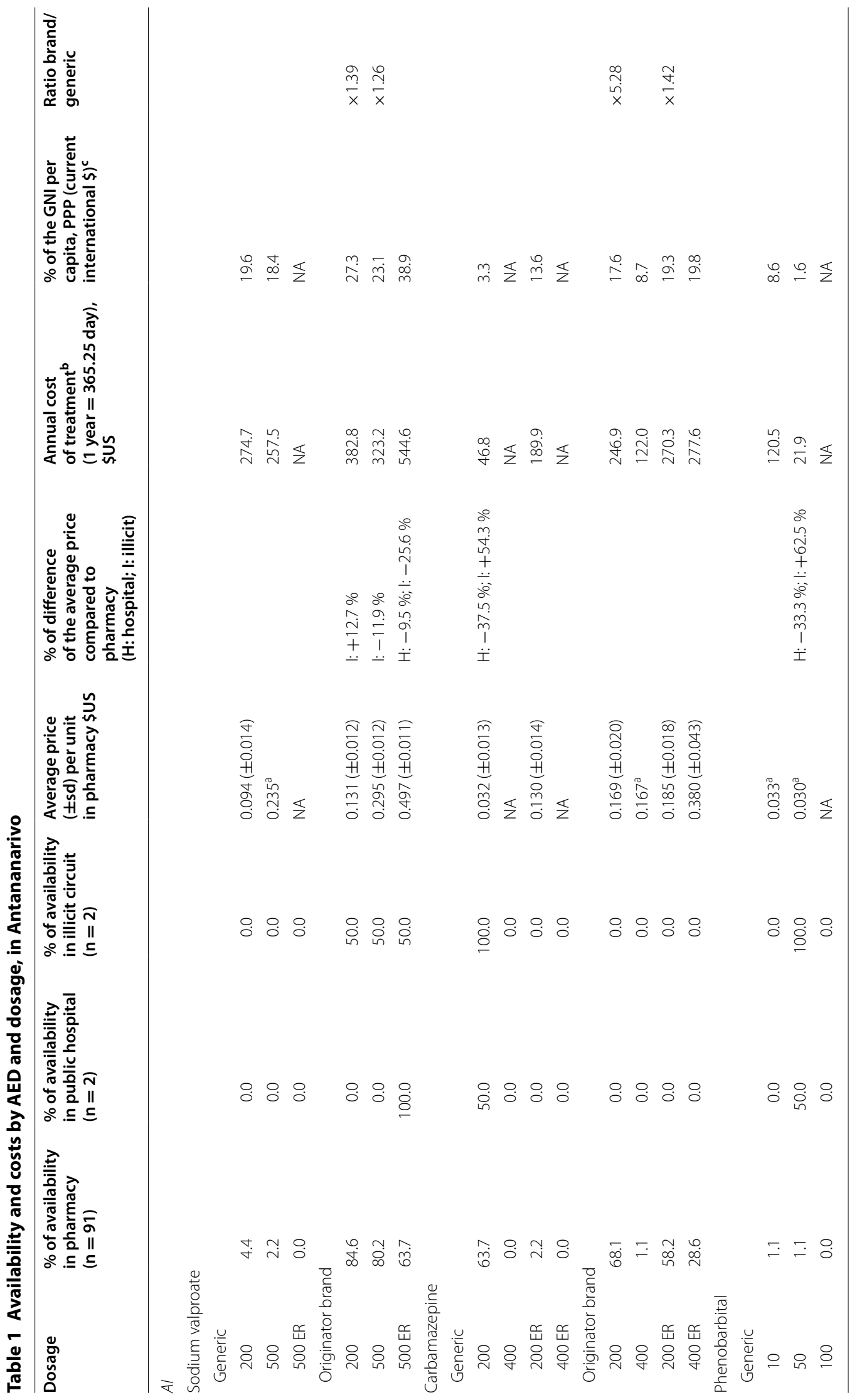




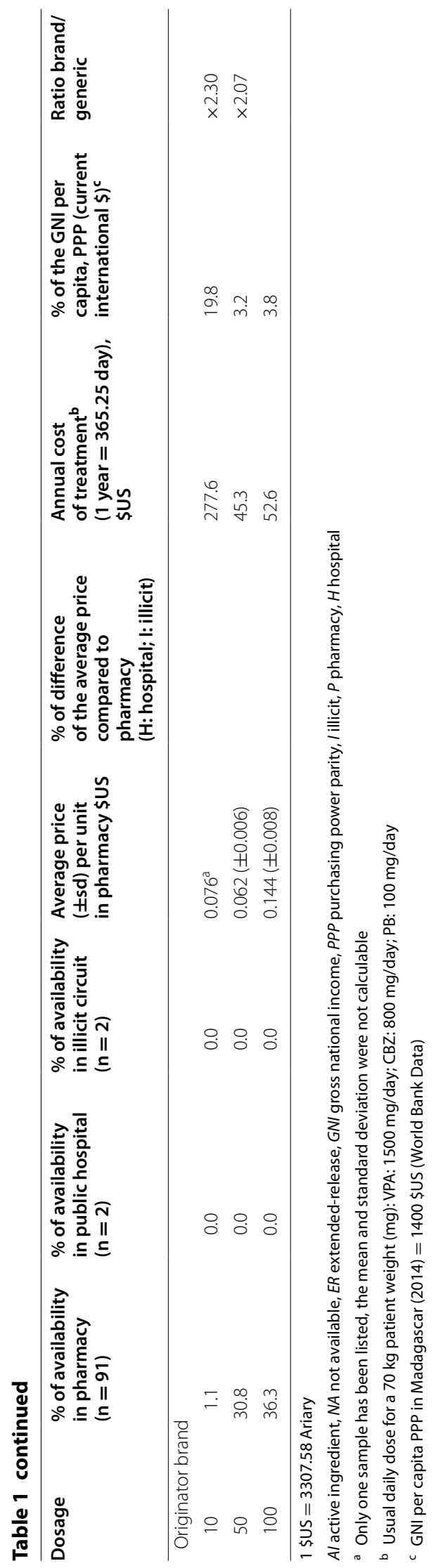


medicines by phone call, was easily and quickly implemented. The main limit of this method is due to the cross-sectional assessment, that provide information in a given position at a given time, that could not be the real availability at any moment. Anyway, it can provide a relevant and a comprehensive focus of the situation in a very large and crowded area with many points to be investigated and with a heavily congested and practically unusable road network. This epidemiological assessment provide data that could contribute to address the financial burden for people with epilepsy in the capital of Madagascar.

\section{Authors' contributions}

$\mathrm{JJ}$ : study design, writing the manuscript, data collection and data analysis and data interpretation; AR: data collection and correcting the manuscript; VR: study design, correcting the manuscript; $\mathrm{MN}$ : data interpretation and correcting the manuscript; EA: data interpretation and correcting the manuscript; CN: study design, correcting the manuscript; P-MP: study design, correcting the manuscript. All authors read and approved the final manuscript.

\section{Author details}

${ }^{1}$ INSERM, Univ. Limoges, CHU Limoges, Department of Pharmacy, UMR_S 1094, Tropical Neuroepidemiology, Institute of Neuroepidemiology and Tropical Neurology, CNRS FR 3503 GEIST, 2 rue du Docteur Marcland, 87025 Limoges Cedex, France. ${ }^{2}$ Hôpital Joseph Raseta Befelatanana, Antananarivo, Madagascar. ${ }^{3}$ Department of Psychiatry, University of Oxford, Oxford, UK. ${ }^{4}$ KEMRI-Wellcome Trust Programme Centre for Geographical Medicine (Coast), Kenya Medical Research Institute, Kilifi, Kenya.

\section{Competing interests}

The authors declare that they have no competing interests.

Received: 3 June 2016 Accepted: 28 September 2016

Published online: 06 October 2016

\section{References}

Ba-Diop A, Marin B, Druet-Cabanac M, Ngoungou EB, Newton CR, Preux PM (2014) Epidemiology, causes, and treatment of epilepsy in sub-Saharan Africa. Lancet Neurol 13(10):1029-1044

Baftiu A, Johannessen Landmark C, Nikaj V, Neslein IL, Johannessen SI, Perucca E (2015) Treatment availability of antiepileptic drugs across Europe. Epilepsia 56(12):e191-e197

Cameron A, Bansal A, Dua T et al (2012) Mapping the availability, price, and affordability of antiepileptic drugs in 46 countries. Epilepsia 53:962-969

Kale R (2002) Global Campaign against epilepsy: the treatment gap. Epilepsia 43(Suppl 6):31-33

Meyer AC, Dua T, Ma J, Saxena S, Birbeck G (2010) Global disparities in the epilepsytreatment gap: a systematic review. Bull World Health Organ 88(4):260-266

Ngugi AK, Bottomley C, Kleinschmidt I, Sander JW, Newton CR (2010) Estimation of the burden of active and life-time epilepsy: a meta-analytic approach. Epilepsia 51(5):883-890

Perucca E (2007) Treatment of epilepsy in developing countries. Br Med J 334:1175-1176

Ratsimbazafy V, Andrianabelina R, Randrianarisona S, Preux PM, Odermatt P (2011) Treatment gap for people living with epilepsy in Madagascar. Trop Dr 41(1):38-39

\section{Submit your manuscript to a SpringerOpen ${ }^{\circ}$ journal and benefit from:}

- Convenient online submission

- Rigorous peer review

- Immediate publication on acceptance

- Open access: articles freely available online

- High visibility within the field

- Retaining the copyright to your article 